\title{
NUMERICAL MODELING OF MACRO-SCALE BRITTLE ROCK CRUSHING DURING IMPACTS
}

\author{
Salah, A. Badr *, Gamal, S. Abdelhaffez
}

Mining Eng. Dept., Faculty of Engineering., king Abdulaziz University, Jeddah, Saudi Arabia

* * Secondment from Mining Engineering Department, Faculty of Engineering, Assiut University, Egypt.

(Received January 22, 2012 Accepted August 17, 2012)

\section{Abstract}

Several machines, such as percussion drills and crushers use the physical effect of compression to crush hard and brittle rocks. These machines are still sized rather by empirical than by scientific approaches. In order to investigate the principles of comminution by compression of single large rock fragment, a numerical model developed by Particle Flow Code "PFC®" program was developed to simulate the dynamics of this system. The model simulates a single rock fragment crushed by a number of fixed kinetic energy ram blows. The simulated fragment is circler granite disk of unit thickness with grain matrix at the range from 2 to $4 \mathrm{~mm}$. The model results indicates that cracks generated due compression are more popular compared to those due shear and this conduct increases with increase of number of hits. The impact energy is consumed mainly in form of friction energy $\approx 52$ to $61 \%$ inside the fragmented matrix while strain energy stays at the range of $\approx 5 \%$. The rock matrix tends to consume more of these energies as number of impacts increases due change to crushed matrix milling and cushioning. The energy consumed in crushing the rock fragment represents at the range from 32 to $45 \%$ of impact energy and tends to decrease as number of hits increase.

Key words: crushing energy - rock fragmentation - Discrete Element Method (DEM) - PFC2D code - crushing energies.

\section{Introduction}

Nowadays, increasing energy costs and raw material prices make it important to look at the efficiency of the manufacturing process. Rock comminution systems consume extensive energy yet nearly $10 \%$ of this energy is effectively relevant to rock disintegration [1-2]. Mineral processing plant is usually starts with the crushing of raw large sized boulders that may go in size up to $0.5 \mathrm{~m}$. Crushers which apply the effect of compression during comminution are strongly recommended for hard and brittle rocks. These crushers use the principle of compression of single particle within the processing zone of the machine. The design of crushing machines depends heavily on crushed rock macro properties (e.g., large boulder physical/mechanical properties) while grinding machine mainly designed based on micro properties (e.g., small particles physical/mechanical properties)[3]. The machine designs of these crushers hardly have 
scientifical bases [3]. Some designers may use empirical approaches based on the hypothesis of the more common Bond [4]. Bemrose and Bridgewater [5] state that: "multiple-impact studies can give empirical data that is useful for the direct application to realistic contexts, but do not generally reveal the basic failure mechanisms. Singleimpact studies can be used to develop an understanding of failure processes and mechanisms, as well as providing useful statistical data that can be used for predictive analysis". In summary, the compression energy distribution inside rock matrix and surrounding media are yet to be clearly understood in quantitive manner thus save consumed energy is possible.

In this research a clear vision into the phenomenon of impact at the macro scale is covered. The research shads light into the macro responses of a rock boulder due dynamic impact utilizing a Discrete Element Method (DEM). The investigation focuses on quantitative estimate of the energies amount consumed by a rock due a repeated ram impact. Algorithms were developed to estimate energy quantities consumed into rock matrix in form of friction and strain energy. The remaining amount of impact energy is expected to be an effective fracturing energy that utilized in true crushing of rock [6-7]. The research utilizes PFC2D a Discrete Element Method (DEM) program (Itasca CG, MN, USA). The program models the movement and interaction of spherical particles by the distinct element method [8]. The calculation method in PFC is a time-stepping with an explicit scheme. PFC2D is able to model a brittle solid, by bonding every particle to its neighbor; the resulting assembly can be regarded as a "solid" that has elastic properties and is capable of "fracturing" when bonds break in a progressive manner. PFC2D contains extensive logic to facilitate the modeling of solids as close-packed assemblies [9-10]. The solid may be homogeneous, or it may be divided into a number of discrete regions or blocks.

\section{Experimental design and methods}

The development of stamp mill model requires an estimate of granite micro properties. Therefore, a granite sample uniaxial tested was simulated by PFC to develop relevant micro granite properties. This process is an iterative in nature where an assumption for micro properties is given for the numerical model and stress-strain curve is obtained numerically. When the stress-strain curves of both model and physical tested granite sample has the same values in terms of uniaxial strength and young's modulus then the developed micro properties is valid and applicable for stamp mill simulation models [11].

\subsection{Materials}

The micro structure of granite rock is heterogeneous with different types of minerals of various mechanical properties (Fig 1a). It is irrelevant to develop a numerical model that replicate the granite rock mineral grains rather a global model with similar macro response is needed. Therefore the PFC model matrix was developed with no specific granite matrix rather a homogenous micro mechanical property was initiated for a collection of desks of size around $2.25 \mathrm{~mm}$ (Fig $1 \mathrm{~b}$ ). The size of the sample later tested in stamp mill model was $6.34 \mathrm{~cm}$ which carries the granite rock micro properties. 


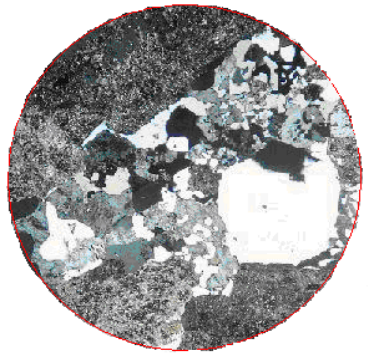

(a)

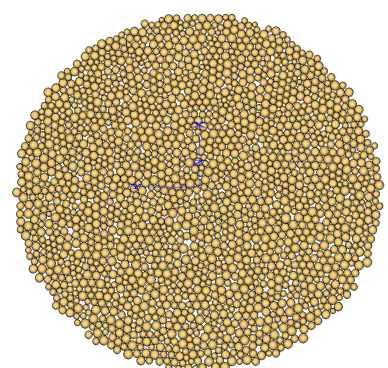

(b)

Figure 1: (a) Typical granite micro structure and (b) model micro structure

\subsection{Develop PFC synthetic material}

The formulation of PFC model requires back analysis of micro granite properties that when tested shall bring similar macro response of actual granite rock. The process is an iterative one where sets of micro properties are given during simulation of an independent core sample by uniaxial tests. Figure 1a shows our developed model to obtain the relevant micro properties for granite sample. When macro response of simulated sample produces similar stress-strain curve comparable to physically tested rock then the input micro properties is accepted. Typically higher strength granite has E modulus $88 \mathrm{GPa}$, UCS of $>200 \mathrm{MPa}$ and Poisson ratio in range from 0.25 to 0.35 [12-13]. Figure 2 shows the numerical experiment model for Uniaxial testing of synthetic granite matrix with corresponding stress-strain curve of physical sample . Table 1 depicts the concluded micro properties that were able to return macro responses within the range of granite rock. This granite synthetic material property was later used as base micro proprieties in experimenting with following ram impact experiment.

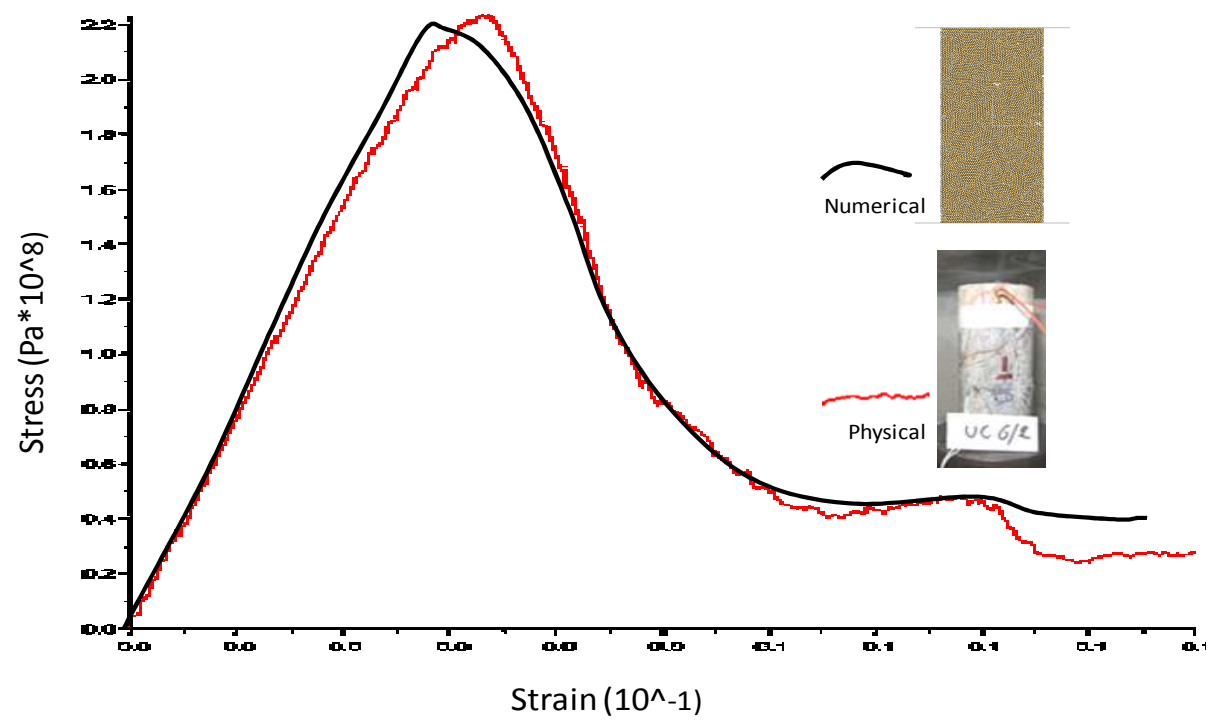

Fig 2: The stress-strain comparison between PFC model and physical test 
Table 1: Results of micro PFC properties returning acceptable macro

granite response

\begin{tabular}{|l|c|c|}
\hline \multicolumn{1}{|c|}{ Parameter } & value & Unit \\
\hline DEM element & $\Phi=2.25$ & $\mathrm{~mm}$ \\
Ball size multiplier & 1.30 & Norm distribution. \\
Ec "elasticty modulus" & 88 & GPa \\
Kn/Ks ratio "normal to shear modulus" & 1 & Isotropic \\
F Friction coefficent for ball & 0.50 & - \\
r Density of ball & 2.63 & $\mathrm{~g} / \mathrm{cm} 3$ \\
s Normal strength of contact bond & $2.0^{*} 10^{8}$ & $\mathrm{~Pa}$ \\
t Shear strength of contact bond & $2.0^{*} 10^{8}$ & $\mathrm{~Pa}$ \\
BC "Boundary conditions" & All Free & - \\
Locked in stress "isotropic" & $1 * 10^{3}$ & $\mathrm{~Pa}$ \\
\hline
\end{tabular}

\subsection{Rock-ram crushing model}

This PFC model simulates the dynamic system of cylindrical cross-section rock fragment hit with a stiff ram (Fig $3 \mathrm{a}, \mathrm{b}$ ). The ram due its mass and active gravity will travel downward a distance of nearly $30 \mathrm{~cm}$ to generate a dynamic impact on sample. The mechanical proprieties of ram domain and sample surrounding walls are depicted in Table 2. The run will continue till the ram reaches a rest position on sample and model reach static equilibrium. Then ram start a new trip down to hit the sample again. The max number of hits was limited at presence of cushioning effect "no more fractures are developed". Table 3 depicts the ram motion indices and the monitoring algorithm to trace output parameters that include ram kinetic energy, strain energy and friction energy within rock sample matrix. Additional monitoring algorithm keep tracking the number of cracks and the type of crack generating mode i.e., compression or shear. 

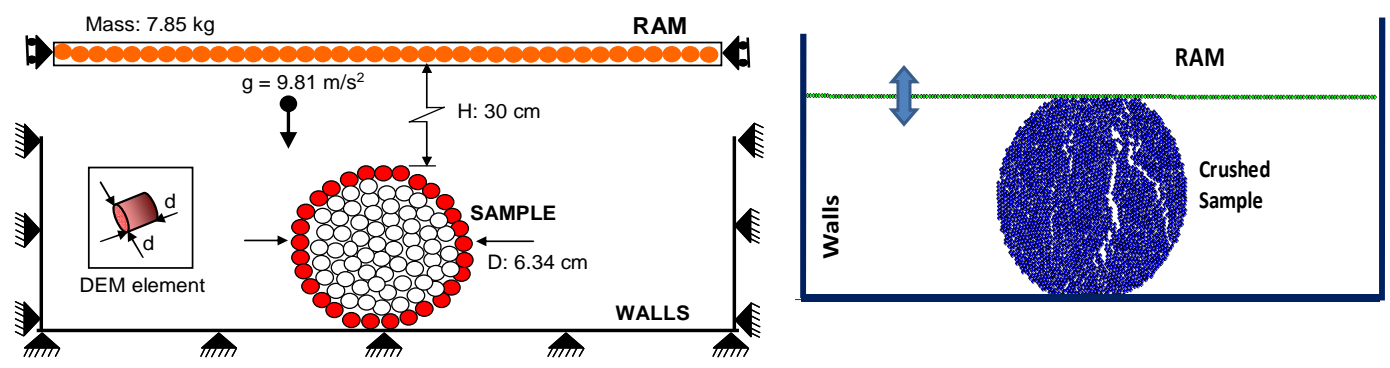

(a)

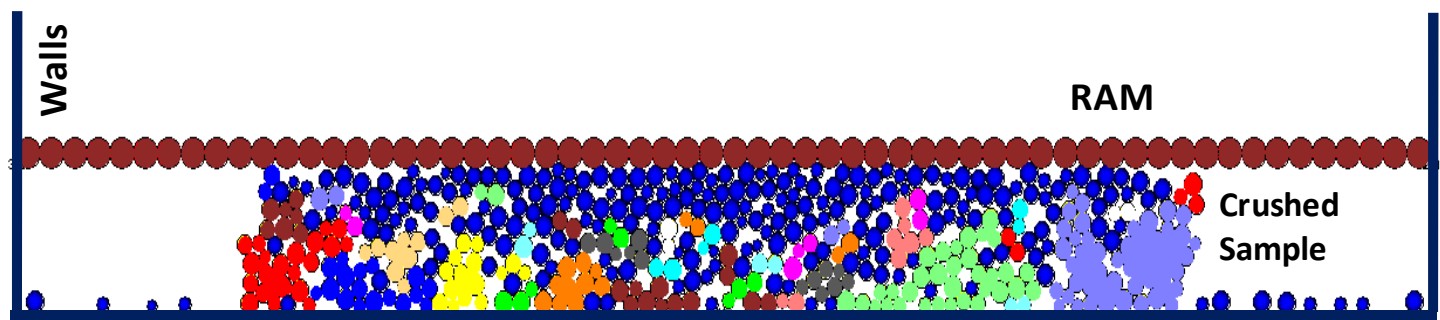

(b)

Figure 3: (a) Stamp mill model outlines and actual PFC model (b) PFC model after sample crushed due repetitive ram hits

Table 2: Set up component properties

\begin{tabular}{|c|l|c|c|}
\hline Component & \multicolumn{1}{|c|}{ Parameter } & Values & Comments/units \\
\hline \multirow{6}{*}{ Ram } & BC (Boundary conditions) & Free Y - Fix X & - \\
& Locked in stress & 0 & $\mathrm{~N} / \mathrm{m} 2$ \\
& Ball size & $\Phi=2.25$ & $\mathrm{~mm}$ \\
& Ball size multiplier & 1 & Mono-sized \\
& Young's modulus at contacts & 8 & $\mathrm{GPa}$ \\
& Norma/shear stiffness ratio & 1 & - \\
& Ball Normal stiffness & $1 \mathrm{e} 12$ & $\mathrm{~N} / \mathrm{m}$ \\
& Ball Shear stiffness & $1 \mathrm{e} 12$ & $\mathrm{~N} / \mathrm{m}$ \\
& Ball Friction coefficient & 0.5 & $\mathrm{~N} / \mathrm{A}$ \\
& Ball density & 8 & $\mathrm{~g} / \mathrm{cm}^{3}$ \\
& Contact bond norm strength & $1 \mathrm{e} 12$ & $\mathrm{~N}$ \\
& Contact bond shear strength & $1 \mathrm{e} 12$ & $\mathrm{~N}$ \\
\hline \multirow{5}{*}{ walls } & Wall surface multiplier & 1.10 & - \\
& $\mathrm{K}_{\mathrm{n}} / \mathrm{K}_{\mathrm{s}}$ & 1 & - \\
& Wall Normal stiffness & $1 \mathrm{e} 12$ & $\mathrm{~N} / \mathrm{m}$ \\
& Wall Shear stiffness & $1 \mathrm{e} 12$ & $\mathrm{~N} / \mathrm{m}$ \\
& Wall Friction coefficient & 0.5 & - \\
& Spin & Fix x, y & - \\
\hline
\end{tabular}


Table 3: Simulation run setup parameters

\begin{tabular}{|l|l|c|c|}
\hline Component & \multicolumn{1}{|c|}{ Parameter } & Values & Comments/units \\
\hline \multirow{5}{*}{ Run mode } & Ram initial speed & 0.00 & $\mathrm{~m} / \mathrm{s}$ \\
& Ram final speed & 5.87 & $\mathrm{~m} / \mathrm{s}$ \\
& Run steps & dependent & $\mathrm{step}$ \\
& Gravity & $-9.81 @ \mathrm{Y}$ & $\mathrm{m} / \mathrm{s}^{2}$ \\
\hline \multirow{5}{*}{ Monitoring } & Joule & N.m \\
& Strain energy & Joule & N.m \\
& Kinetic energy & Joule & N.m \\
& Friction energy & Number & - \\
& Total number of cracks & Number & - \\
& No. of shear bond cracks & Number & - \\
\hline
\end{tabular}

\section{Results and discussions}

The resulting response from stamp mill model at progressive number of hits is shown in Figure 4. The first hit caused matrix pulverization at contact area without through fracture. The second hit developed a through fracture and more pulverizing. The response mode at third and latter hits typically shows pulverizing effect "milling" and surface cushioning is evident at hit 14 further hits produce similar response.

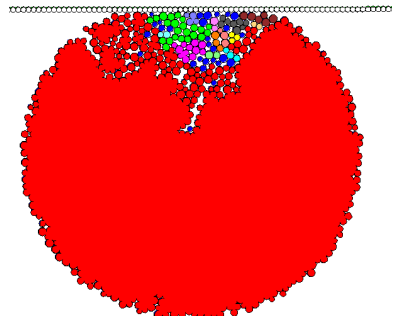

No 1 hit

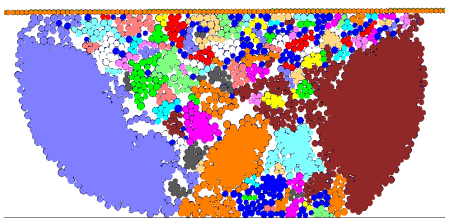

No 7 hit

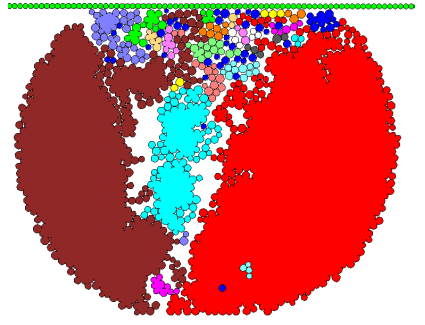

No 2 hit

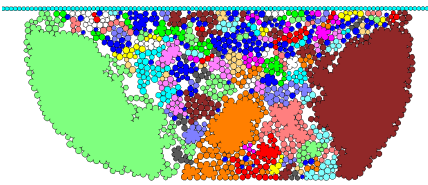

No 8 hit

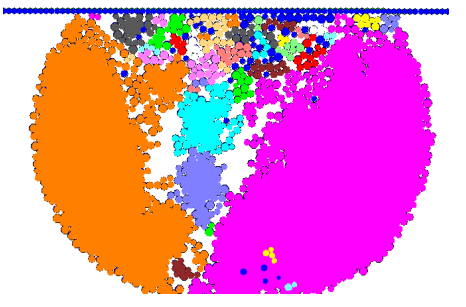

No 3 hit

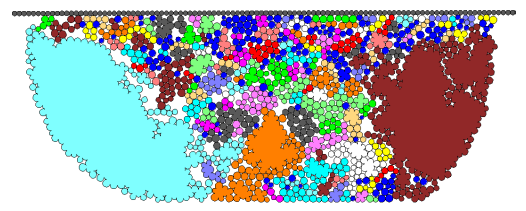

No 9 hit

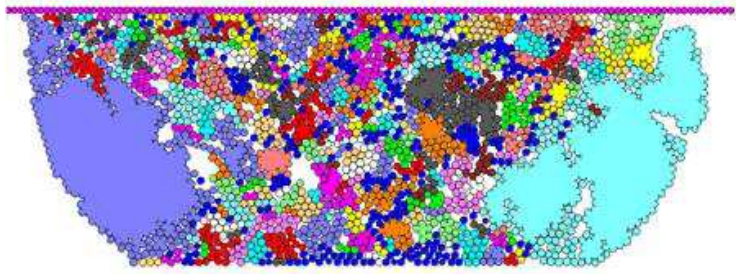

No 13 hit

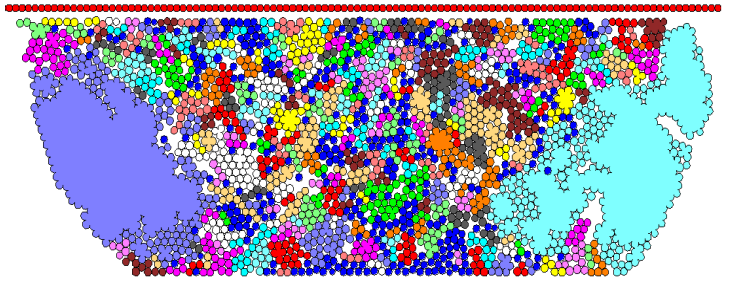

No 14 hit

Figure 4: Modeled granite failure styles as per progressive stamp hits 
An algorithm in FISH programming language (PFC built-in facility) was used to collect model system energies including (e.g., strain and friction energy)

Figure 5 depicts an insight into the change of energy based on types during progressive impacts. Impact energy dissipates into the surrounding recipients including sample matrix in form of strain and friction energy and useful fracturing energy. The strain energy would peaks at the start of the ram hits then due elasticity and lack of lock-in confinement dissipates at equilibrium. This response replicates behavior of a single particle at process zone of a crusher.

Figure 5 also shows that the friction energy continues to increase as number of hits increases. PFC built on principle of conservation of energy thus the friction energy continues to build up "not dissipating". In reality friction energy will dissipate in form of sound and heat which PFC can not simulate. Figure 6 shows the net friction energy added to the system after each hit. The added friction energy shows minor change "leveled" at each hit except for the first hit.

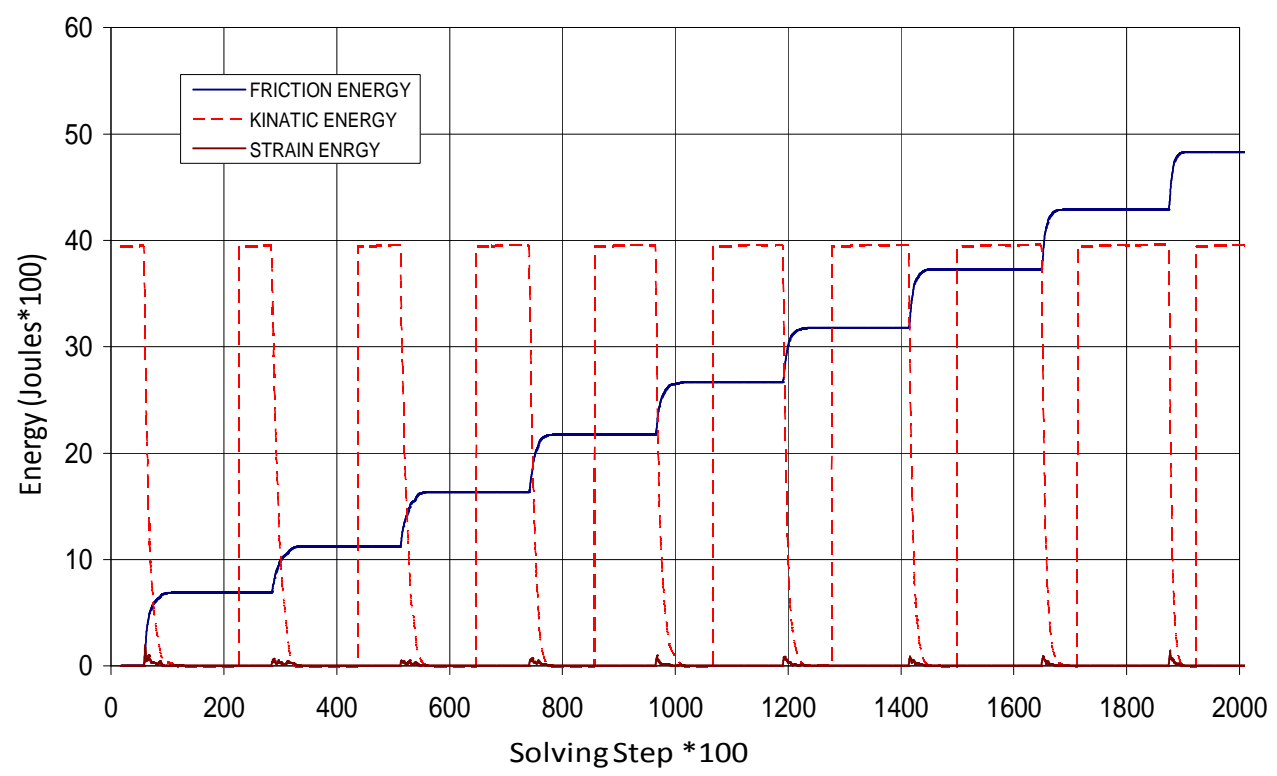

Figure 5. The energy mode change during progressive stamp impacts 


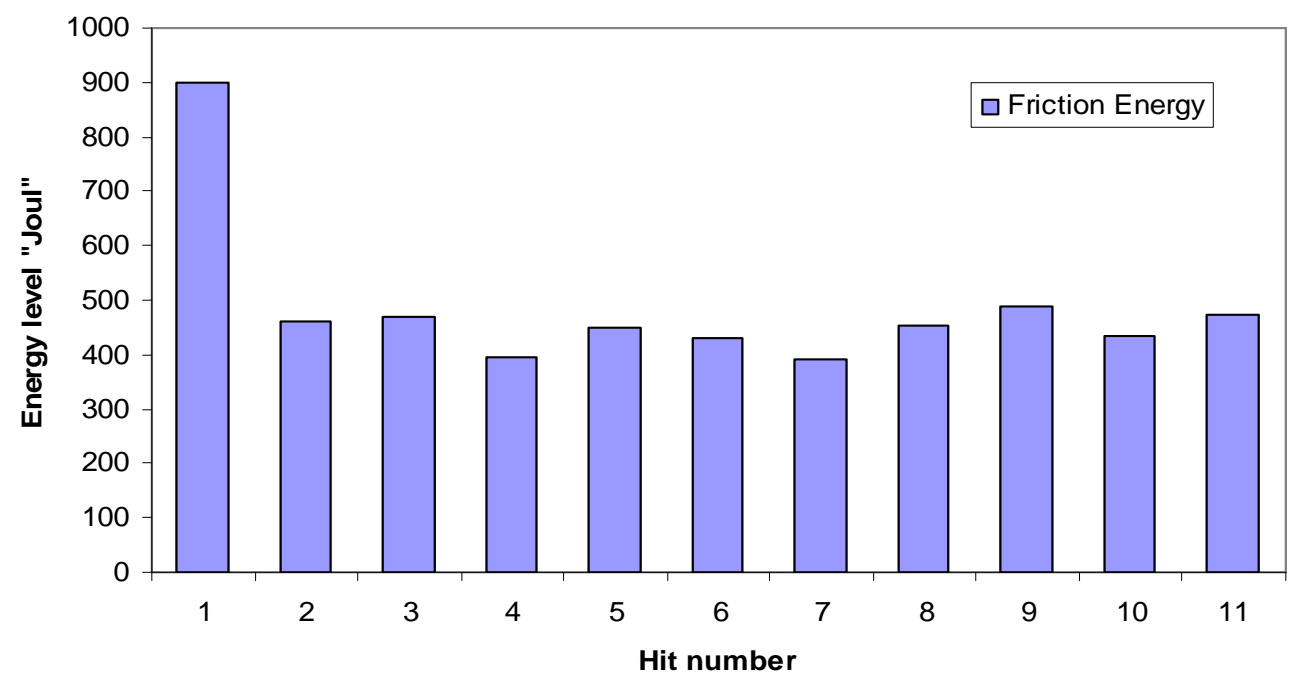

Figure 6. The net friction energy added to system after each stamp hit.

Figure 7 shows an example of energies variation during the first ram hit with number and type of cracks generated. The strain energy releasing fashion follows closely resulting crack population. As more cracks generated strain energy starts dissipating. The added surface area due crack increased population will give relevant chances for strain energy to release thus dissipate. The strain energy will be arrested as cracking stabilizes due generated temporary micro confinement. Further increase in crack population would then generate further micro confinement and more strain energy arresting.

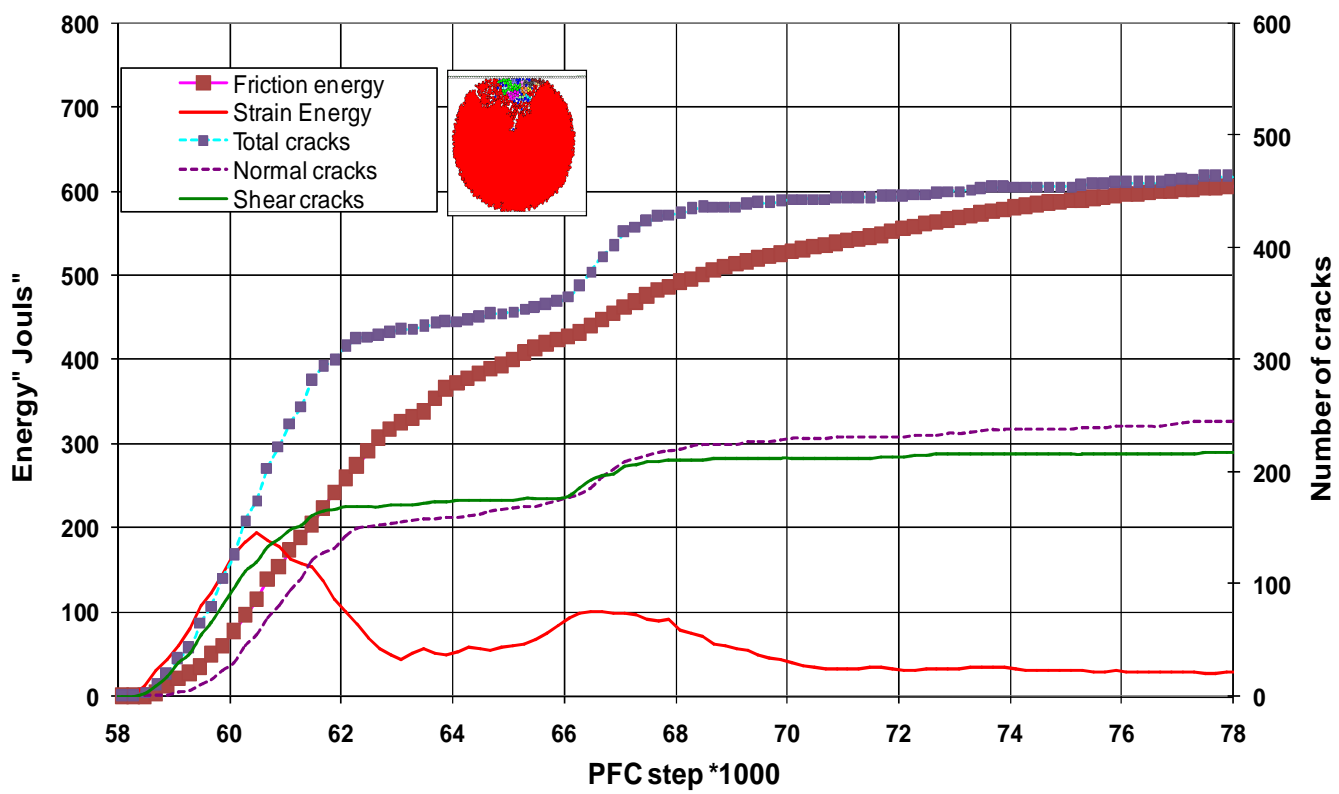

Figure 7 Energy variations and crack numbers at the first stamp hit 
Figure 8 depicts the population for both shear and compression type cracks. The compression cracking predominates the resulting crack populations. This confirms to the known fact that comminution due compression is the most effective crushing mode in industrial crushering machines.

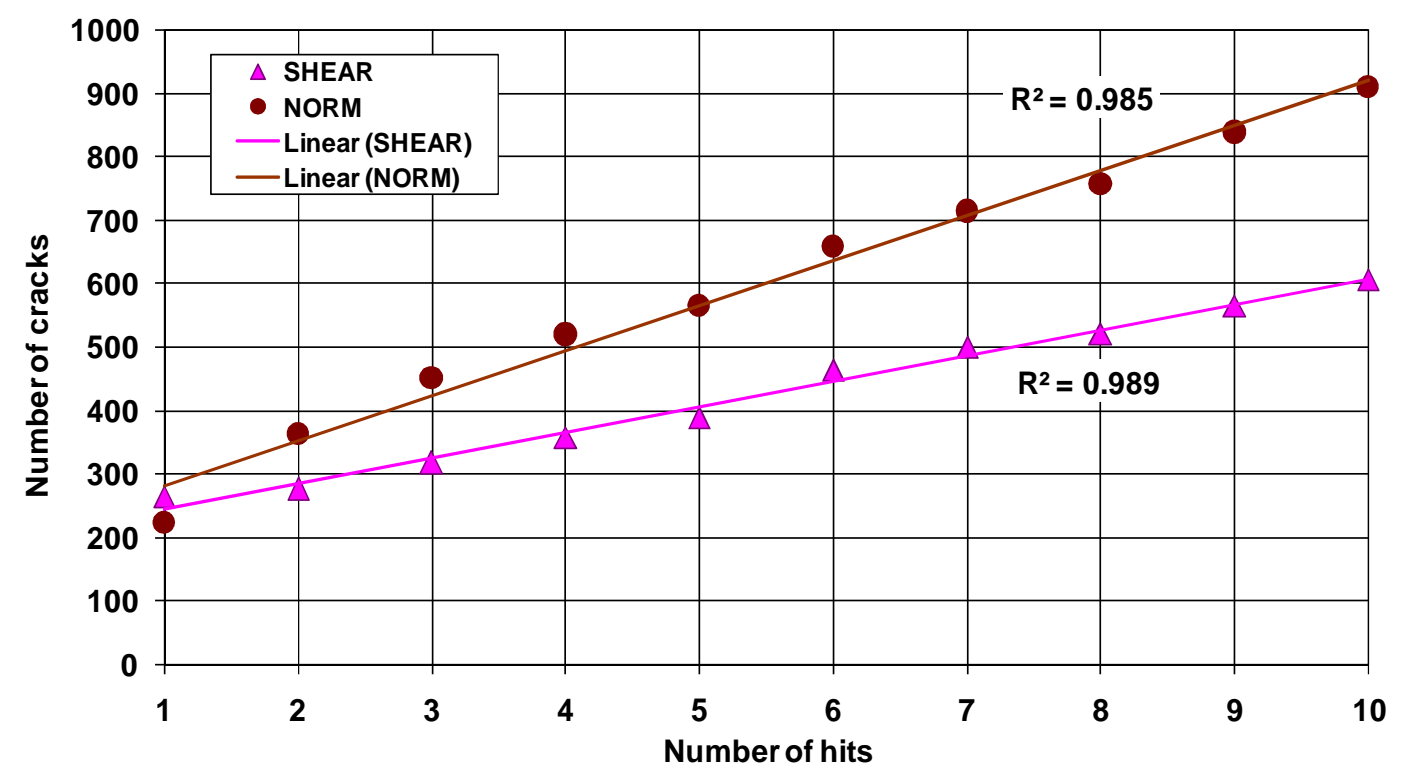

Figure 8 Crack populations per type of cracks

Figure 9 depicts the changes in amounts of system energies based on type. Principles of energy conservation depicts that the kinetic energy delivered to the system is distributed among: strain, friction and fracturing energy "fracturing energy". The "fracturing energy" was estimated as from the following equation:

Fracturing energy $=$ Kinetic energy $-($ Strain energy + Friction energy $)$

The strain energy tends to increase ( $\max 5 \%$ ) due increase of micro-confinement as number of crack increase. The friction energy tends to increase as number of hits increase which is more related to the mode of comminution that changed into milling rather crushing. The fracturing energy tends to decrease with increased number of hits since part of input energy would be consumed in form of strain energy and friction energy. 


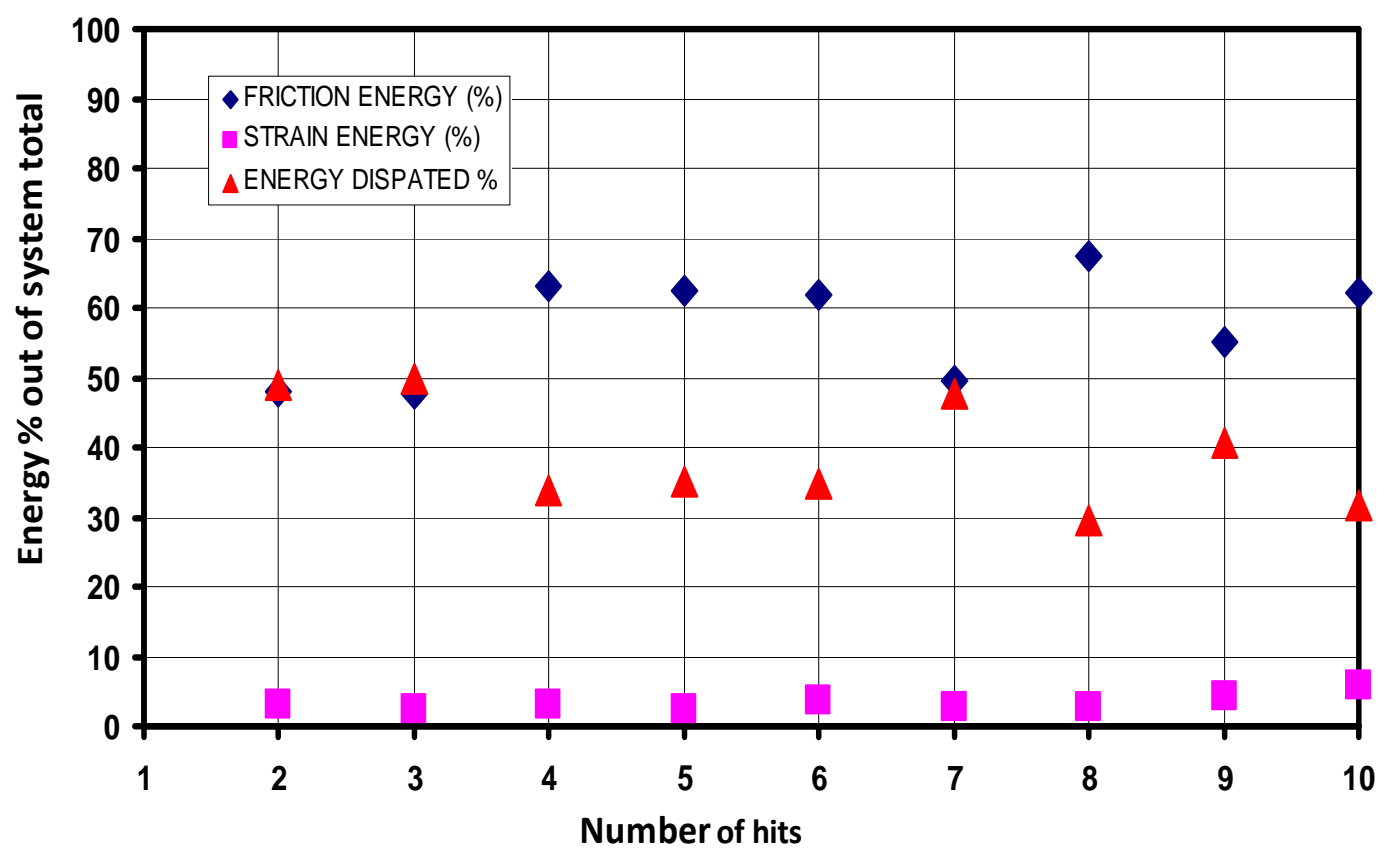

Figure 9 Energy distribution during different stamp hits

\section{Conclusions.}

The model shows that the micro behavior of crushed rock is complex but possibility can be numerically simulated. The model was able to estimate quantitatively different energies due stamping energy. The model was also able to predicate the population of different fracturing modes "compression or shear". The cracks generated due compression are more popular compared to those due shear and this conduct increases with increase of number of hits. The strain energy role in crushing system is considered as minor consumer for applied energy. The strain energy build up may reach up to 5\% of stamping energy. The friction energy may consume up $70 \%$ of system energy. The useful fracturing energy would be less than $50 \%$ and tends to decrease as number of hits increase. The overall behavior of the system depicts that the friction energy will increase with number of hits while the useful cracking energy tends to decrease due cushioning effect. Different rock mechanical properties would possibly change the ranges of energy distribution mentioned due the changes in micro scale properties.

Future work would possibly include simulate different rock types to develop a rational criterion relating micro and crushing characteristics of different rocks. 


\section{References}

[1] Kwade, A. Scriptum Zerkleinern und Dispergieren in Ruhrwerkskugelmuhlen $10^{\text {st }}$ Ipat, Institute for Particle Technology, Technical University of Braunsschweig,Pp 123-131, Germany, (2000).

[2] KWADE, A. Scriptum Grinding and dispersing with stirred media mills Research and Application. 21 ${ }^{\text {st }}$ Ipat, Institute for Particle Technology, Technical University of Braunsschweig, Pp 78-85, Germany, (2005).

[3] Georg Unlanda, Piotr Szczelinab: Coarse crushing of brittle rocks by compression, Int. J. Miner. Process. Vol. 74S, pp. S209-S217, (2004).

[4] Bond, F.C., "Crushing and grinding calculations - Part I", British Chemical Engineering, Vol. 6, pp. 378-385, (1960).

[5] Bemrose, C.R and Bridgwater, J: A review of attrition and attrition test methods, Powder Technology, Vol. 49, pp. 97- 126, (1987).

[6] Djordjevic, N. Discrete element modeling of the influence of lifters on power draw of tumbling mills. Minerals Engineering, Vol. 16, pp. 331336, (2003).

[7] Kafui, K. D. and Thornton, C. Numerical simulations of impact breakage of spherical crystalline agglomerate. Powder Technology, Vol., 109, pp. 113-132, (2000).

[8] Djordjevic, N., Shi, F.N., and Morrison, R. D. "applying discrete element modeling to vertical and horizontal shaft impact crushers". Minerals engineering, Vol. 16, pp. 983-991, (2003).

[9] Refahi, A., Aghazadeh Mohandesi J., and Rezai, B. "comparison between bond crushing energy and fracture energy of rocks in a jaw crusher using numerical simulation". The journal of the southern African institute of mining and metallurgy, Vol. 9. pp. 709 -717, (2009).

[10] Potapov, A.V and Campbell, C.S. "Computer simulation of impactinduced particle breakage", Powder Technology, Vol. 81, pp. 207-216, (1994).

[11] Itasca CG, MN, USA: PFC2D code Manual, (2004).

[12] Weber, U. and Langlois, D "The effect of grinding media performance on milling and operational behavior "The journal of the southern African institute of mining and metallurgy, Vol. 110 pp.147-152, March (2010).

[13] Oluokun, Francis, A. Edwin Burdette,. G. and Harold Deatherage, J. "Young's modulus, poisson's ratio, and compressive strength relationships at early ages" ACI Materials Journal, Vol. 88, No. 1, pp. 3-9, (1991). 


\section{تطبيق النمذجة العددية على تهشيم الصخور بالكسارة الدقاقة}

العديد من معدات التكسير مثل الكسارات الدقاقة والتى تعتبر أن تكسير الصخور الصلدة والهشة ينتج من تأثير قوة الضغط بدرجة كبيرة. مازال النمط التجريبي هو السائد فى محاولة فهم سلوك وأداء الكسارات، أما النمط الاستتباطي العلمي قاصر فى تفسير كثثر من السلوك الداخلي للصذر أثناء عمليات التكسير ـ لذلك كان الاتجاه حثيثا نحو محاولة تطبيق النذجة العددية لفهم أداء وتفسير سلوك الحبير العبيات أثناء عملة التكسير .

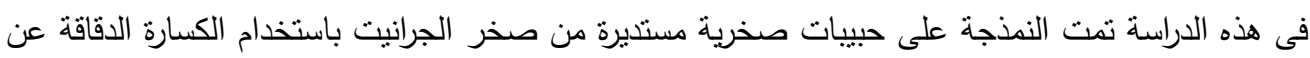
طريق نمذجة الطاقة الحركية النى تؤدى إلى تكسير الحبيبات.

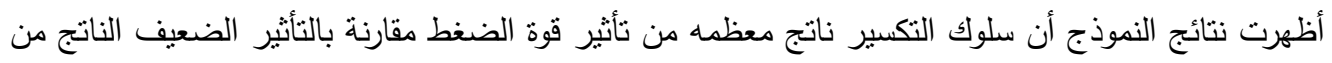
قوة القص، وهذه الظاهرة تزداد وضوحا بزيادة عدد الطرقات. تثنل طاقة الاحتكاك 52-61\% من الطاقة الناتجة من التكسير بالتصادم بينما الطاقة المستهلكة فى صورة طاقة الانفعال تمثل تقريبا 5\% فقط.

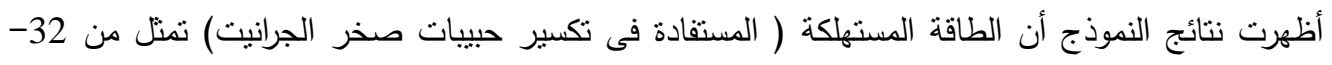
55\% من الطاقة الكلية الناتجة من عمليات التصادم وهذه النسبة تميل الى التناقص مع زيادة عدد الطرقات. 